Editorial

\title{
Editorial: Students with Disabilities in Higher Education
}

\author{
Geert Van Hove ${ }^{1,2, *}$, Alice Schippers ${ }^{2,3}$ and Minne Bakker ${ }^{2}$ \\ ${ }^{1}$ Department of Special Needs Education, Ghent University, 9000 Ghent, Belgium; E-Mail: geert.vanhove@ugent.be \\ 2 Department of Medical Humanities, VU University Medical Centre/Amsterdam Public Health, 1081 BT Amsterdam, The \\ Netherlands; E-Mail: mi.bakker@vumc.nl \\ ${ }^{3}$ Disability Studies in the Netherlands, 3811 HR Amersfoort, The Netherlands; E-Mail: aliceschippers@disbilitystudies.nl \\ * Corresponding author
}

Submitted: 22 October 2018 | Published: 6 December 2018

\begin{abstract}
This editorial will at first present the thirteen different articles published in the issue. On a second level, we will focus on "overarching themes". Those themes should be understood as links between the different articles in this volume.
\end{abstract}

\section{Keywords}

Disability Studies; higher education; students

\section{Issue}

This editorial is part of the issue "Students with Disabilities in Higher Education", edited by Geert Van Hove (Ghent University, Belgium/VU Amsterdam, The Netherlands), Minne Bakker (VU Amsterdam, The Netherlands) and Alice Schippers (Disability Studies in the Netherlands/VU Amsterdam, The Netherlands).

(C) 2018 by the authors; licensee Cogitatio (Lisbon, Portugal). This article is licensed under a Creative Commons Attribution 4.0 International License (CC BY).

\section{Introduction}

This issue of Social Inclusion contains a collection of thirteen articles concerning students with disabilities in higher education. We firmly believe this collection opens up some new perspectives on the "problematic intersection", dixit Margaret Price (2011, p. 5), between (mental) "disability" and "the most important common topoi of academe". The latter include: rationality, criticality, presence, participation, resistance, productivity, collegiality, security, coherence, truth and independence.

Our articles are linked with Austria, Belgium, Egypt, Germany, Israel, Norway, South Africa, the Netherlands, the US and the UK. We are convinced the presented collection can help us get better insights into the above mentioned problematic intersection, and this across countries, labels/diagnostic categories-from a large sample of "all students with a label" in Austria over to specific groups like hard of hearing students, Deaf students, students with bipolar disorder, students with lived experiences of mental health problems, students with visual impairments and students with physical impairmentsbut also beyond a specific "category of actors" within the field of higher education institutions such as administrative staff, lectors and professors, students with and without label, HR-experts within the labour market, etc.

This editorial will at first present the thirteen different articles. On a second level we will focus on "overarching themes". Those themes should be understood as links between the different articles in this volume.

\section{Short Presentation of the Articles}

In a very personal article by Jonathan Harvey, "Contemporary Social Theory as a Tool to Understand the Experiences of Disabled Students in Higher Education", we can observe how the introduction of contemporary social theoretical frameworks (Foucault, Derrida, Deleuze and Guattari, Braidotti) can help demystify the experience of disabled students (Harvey, 2018). This text is a wakeup call to stop the excessive use of practical-technical solutions and to balance one-size-fits-all solutions with solid theory.

In the article by Roth, Pure, Rabinowitz and Kauffman-Scarborough (2018) we get a presentation of a Disability Awareness Training and Empowerment 
program as developed in/for one campus. The authors are showing how they combined a literature review to construct the program in close cooperation with all stakeholders while using a kind of action research plan. At the end of the article we are confronted with a nice new discussion opening up the question of whether it is necessary to offer such training packages also to students without labels.

We learn from Robert Aust (2018), in his article "Disability in Higher Education: Explanations and Legitimisation from Teachers at Leipzig University", that an analysis of the perspectives of staff members of an institution of higher education vis à vis students with disabilities shows that a lot of the medical/individual perspective on disability is still a reality. The author is introducing the United Nations Convention of the Rights of Persons with Disabilities (UNCRPD) as a tool to remove barriers connected with this medical model thinking, replacing them for more human rights based practices.

In "Learning Experiences of Students Who Are Hard of Hearing in Higher Education: Case Study of a South African University", Bell and Swart (2018) show us that students who are hard of hearing in South Africa (as in a lot of other countries) are accepted but, once there, don't get the necessary support based on the framework of "reasonable accommodations". Analysis of lived experiences of students themselves are leading to recommendations for teaching and learning as well for curricula transformation.

The article by Büscher-Touwen, De Groot and Van Hal (2018), "Mind the Gap Between Higher Education and the Labour Market for Students with a Disability in the Netherlands", reveals that those who finish higher education are confronted with a gap in the transition to the regular labour market. Several factors seem quintessential to understand this phenomenon: it seems there are no stable data and nobody organizes a follow up about the transition; it seems different policy makers don't see this group of young adults as their chore business, and that the regular labour market shows the same attitudinal prejudices as the higher education sector.

In Kermit and Holiman (2018) we learn that downgrading social aspects of the inclusion of Deaf students, due to heavily focusing on the academic chapter of the study trajectory, leads to little interaction with hearing students. Central to this diagnostic group is the knowledge of teachers regarding intercultural communication and visually oriented instruction.

In "Designing a Model for Facilitating the Inclusion of Higher Education", du Toit (2018) defends the statement that, as students with special needs in higher education are seen as real students, they should get the opportunity to go through an international experience. An in-depth analysis of the South African situation shows how many different role players are involved and could be-if they worked together-for incoming and outgoing students with special needs in pre-departure, study and return phase.
Zaussinger and Terzieva (2018) describe a large scale research project in Austria. The large data set is combined with a contemporary interpretation of stigma theory. We learn what factors lead to fear for stigmatisation, but also what characteristics of a program play a role in self-identification of students and their willingness to speak openly about their needs and necessary accommodations.

In "Barriers to Higher Education for Students with Bipolar Disorder: A Critical Social Model Perspective", authors Kruse and Oswal (2018) are making use of the critical social model framework to analyse the lived experience of one of the authors with the label of bipolar disorder. This analysis shows the (hidden) ableist assumptions and the parallel oppression experienced by the students. This paper also brings in a lot of practical recommendations to solve certain problems.

In Carette, Van Hove and De Schauwer (2018), the authors try to introduce the experiences of "mad students" and their attempts to disclose their mental health problems. Worldwide initiatives of psycho-education and information about mental illness seem to fail if they don't install/give support to simple communication about the expectations and needs of mad students. While young students just want help, Higher Education institutions keep a naïve belief that providing information about psychological well-being and mental health can be seen as a solution for several problems.

Research by Almog (2018) reveals a lot about "identity constructions" of students in higher education as both being disabled and being a student. The costs and the benefits related to the chosen positions are balanced in an article that depends heavily on the lived experiences and expertise of the students themselves.

Lord and Stein (2018) introduce Egypt as an in-depth case study to confront the realities of developing countries with the framework of the UNCRPD. As we can expect, an enormous amount of barriers are observed and a human rights-inspired way of working is presented to move the agenda on micro, meso- and macro level. It can be seen that problems as described here can also be found in so called developed countries.

The commentary by Benjamin Ostiguy, "The Inherent Value of Disability in Higher Education", introduces the philosophy of Arne Naess and his framework of Deep Ecology to improve our capacity to understand, value and to give support to students with disabilities. The Deep Ecology framework destabilizes the existing structures and ideology of "normalcy" on a campus.

\section{Overarching Themes}

When we analyse the different articles presented here more in depth we can find several themes and bridges between them.

We know from historians working in Disability Studies (Stiker, 2000) that persons with a label always have been silenced and marginalized. It is remarkable that we 
could build a collection of articles where the voices of students with special needs are so prominent. A lot of the authors based (part of) their research on the lived experiences of these students, and we think we may say that they really followed the basic principle of the Disability Studies field: "nothing about us without us".

With the exception of one article using large numbers of participants, most authors in this volume are using qualitative research methodologies (Hammarberg, Kirkman, \& de Lacey, 2016). Most of the time qualitative research methods are used to answer questions about experiences, meaning and perspectives, from the standpoint of the participant. It is clear that in this journal the "voice" of the students helps us learning about the way they experience learning/living trajectories in higher education institutions.

It is good to see that some of our colleagues feel the need to rely on theoretical frameworks and concepts, like the work of Foucault, Derrida, Deleuze and Guattari, Braidotti, the Stigma theory, the framework of Critical Social Model, Deep Ecology of Naess, ideas coming from Mad Studies, the Social Identity Theory, the ExplanatoryLegitimacy-Theory, the Ableism framework and more. These theoretical frameworks guide them through a critical analysis of different realities. In this way these articles are following authors like Siebers (2008) who are introducing theory to show the complex nature of disability and the inadequacy of a one-size-fits-all theorizing of the phenomenon.

To think about inclusion of students with disabilities in higher education goes hand in hand with thinking about a broader spectrum of themes. It (also) has to do with curricula, the transition to the labour market, identity construction, international study experiences, etc. It shows how the study of this phenomenon "can lead to the identification of novel veins of inquiry, bolster critical analyses, and help facilitate meaningful change in uncertain times" (Ostiguy, 2018, p. 241).

\section{Conclusion}

Although we can rely on existing binding international legal frameworks, like the UNCRPD, this does not necessarily lead to a human rights-based practices. In the era of neo-liberalism, students are still seen as individually responsible and are heavily dependent on the goodwill of individual lecturers.

We hope the readers can enjoy the different papers and will feel encouraged to confront their own practices in Higher Education with the analysis and insights of our articles.

\section{Conflict of Interests}

The authors declare no conflict of interests.

\section{References}

Almog, N. (2018). "Everyone is normal, and everyone has a disability": Narratives of university students with visual impairment. Social Inclusion, 6(4), 218-229.

Aust, R. (2018). Disability in higher education: Explanations and legitimisation from teachers at Leipzig University. Social Inclusion, 6(4), 125-136.

Bell, D., \& Swart, E. (2018). Learning experiences of students who are hard of hearing in higher education: Case study of a South African university. Social Inclusion, 6(4), 137-148.

Büscher-Touwen, M., De Groot, M., \& Van Hal, L. (2018). Mind the gap between higher education and the labour market for students with a disability in the Netherlands: A research agenda. Social Inclusion, 6(4), 149-157.

Carette, L., Van Hove, G., \& De Schauwer, E. (2018). Title to be added. Social Inclusion, 6(4), 207-217.

du Toit, N. (2018). Designing a model for facilitating the inclusion of higher education international students with disabilities in South Africa. Social Inclusion, 6(4), 168-181.

Hammarberg, K., Kirkman, M., \& de Lacey, S. (2016). Qualitative research methods: When to use them and how to judge them. Human Reproduction, 31(3), 498-501. https://doi.org/10.1093/humrep/dev334

Harvey, J. (2018). Contemporary social theory as a tool to understand the experiences of disabled students in higher education. Social Inclusion, 6(4), 107-115.

Kermit, P. S., \& Holiman, S. (2018). Inclusion in Norwegian higher education: Deaf students' experiences with lecturers. Social Inclusion, 6(4), 158-167.

Kruse, A. K., \& Oswal, S. K. (2018). Barriers to higher education for students with bipolar disorder: A critical social model perspective. Social Inclusion, 6(4), 194-206.

Lord, J. E., \& Stein, M. A. (2018). Pursuing inclusive higher education in Egypt and beyond through the Convention on the Rights of Persons with Disabilities. Social Inclusion, 6(4), 230-240.

Ostiguy, B. J. (2018). The inherent value of disability in higher education. Social Inclusion, 6(4), 241-243.

Price, M. (2011). Mad at school. Rhetorics of mental disability and academic life. Ann Arbor, MI: University of Michigan Press.

Roth, D., Pure, T., Rabinowitz, S., \& KauffmanScarborough, C. (2018). Disability awareness, training, and empowerment: A new paradigm for raising disability awareness on a university campus for faculty, staff, and students. Social Inclusion, 6(4), 116-124.

Siebers, T. (2008). Disability theory. Ann Arbor, MI: University of Michigan Press.

Stiker, H.-J. (2000). A history of disability. Ann Arbor, MI: University of Michigan Press.

Zaussinger, S., \& Terzieva, B. (2018). Fear of stigmatisation among students with disabilities in Austria. Social Inclusion, 6(4), 182-193. 


\section{About the Authors}

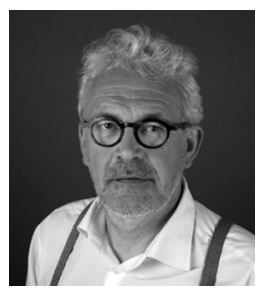

Geert Van Hove, Prof. Dr., works at Ghent University and at the VUmc in Amsterdam, in the field of Disability Studies.

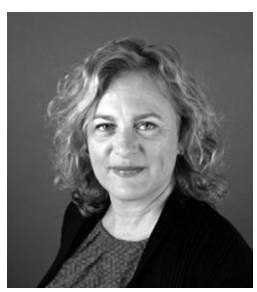

Alice Schippers, Dr., is Executive Director at Disability Studies in the Netherlands and Researcher at the VUmc, Department of Medical Humanities.

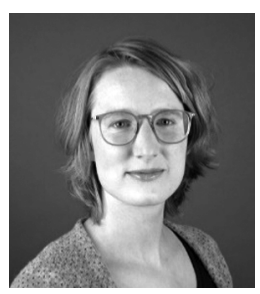

Minne Bakker, Dr., works as Postdoc Researcher at the VUmc, Department of Medical Humanities. 